\title{
Persiljan ja porkkanan siemenlevintäiset sienet Suomessa
}

\author{
Risto TAHVONEN \\ Helsingin yliopiston kasvipatologian laitos, 00710 Helsinki 71
}

\section{Seed-borne fungi on parsley and carrot}

Risto TAHVonen

Department of Plant Pathology, University of Helsinki, 00710 Helsinki 71

\begin{abstract}
In this study the seed-borne fungi on 36 parsley and 57 carrot seed lots are clarified. These were for sale in Finland during the years 1969-1975.

Alternaria dauci (Kühn) Groves \& Skolko was found on $52 \%$ of carrot seed lots. The mean of the fungus capacity on the infected seed lots was $7.2 \%$. Stemphylium radicinum (Meier, Drechster \& Eddy) Neergaard occurred on $39 \%$ of parsley and $58 \%$ of carrot seed lots. The fungus capacity on the infected seed lots was $10 \%$ on parsley and $6 \%$ on carrot. Septoria petroselini Desm. was found on every parsley seed lot excluding one. The fungus capacity varied from $3-37 \%$. On the parseley and carrot seeds occurred 31 other fungus genera and species, which were not important to the germination and emergence of seedlings. The commonest saprophyte was Alternaria tenuis auct.

The soaking of carrot seeds in an $0.2 \%$ aqueous suspension of thiram for 6,12 and $24 \mathrm{~h}$ at $30^{\circ} \mathrm{C}$ and the thiram dust treatment controlled Alternaria dauci and Stemphylium radicinum, but the soaking for 12 and 24 h lowered the emergence of seedlings. A low temperature $\left(13^{\circ} \mathrm{C}\right)$ during the emergence of seedlings reduced the damping-off caused by $A$. dauci and $S$, radiciunm.
\end{abstract}

Porkkana on kaalien ja sipulien ohella tärkein avomaan vihanneskasvi Suomessa. Persilja on tillin ohella käytetyin maustevihannes. Vuosittain maahan tuodaan porkkanan siementä $10300-18700 \mathrm{~kg}$ ja persiljan siementä $1200-3100 \mathrm{~kg}$ (Yllö 1972, 1973, 1975, 1976). Puutarhakasvien siementarkastuksen yhteydessä ei Suomessa ole siemenen terveystarkastusta.

Porkkanan siemenlevintäisistä sienistä ovat tärkeimpiä Alternaria dauci (Kühn) Groves \& Skolko ja Stemphylium radicinum (Meier, Drechsler \& Eddy) Neergaard. S. radicinum aiheuttaa porkkanalla taimipoltetta, lehtien kuolemista ja siemensadon alenemista (NEERGAARD 1945). Sieni on myös merkittävä varastotuhosieni (MUKULA 1957). A. dauci aiheuttaa porkkanalla taimipoltetta ja lehtien kuolemista (NeERgaARd 1945). Halkilahti (1972) on tutkinut Suomessa tarkastusvuosina $1967 / 68,1969 / 70$ ja 1970/71 porkkanan siementavaran $A$. dauci- ja $S$. radicinum-määriä. 
Persiljan siemenlevintäisistä sienitaudeista ovat tärkeimpiä Septoria petroselini D ssm. ja Stemphylium radicinum. S. petroselini on hyvin usein persiljan siemenissä (NEERGAARD 1951) ja aiheuttaa persiljan laatua alentavaa lehtilaikkua, jota on esiintynyt koko Suomessa tekijän havaintojen mukaan vuosina 1971-77 erittäin runsaana myöhäisessä syyspersiljassa ja kasvihuoneessa talvehditettavassa persiljassa. S. radicinum aiheuttaa persiljalla samoja vioituksia kuin porkkanalla (NEERGAARD 1945).

Porkkanan siemenlevintäiset sienet voidaan tehokkaimmin torjua liottamalla siemeniä $0.2 \%$ :ssa tiraami-suspensiossa 24 t $30^{\circ}$ C:ssa (Maude 1966). Suomessa vihanneskasvien peittaukseen suositellaan tiraami-kuivapeittausta, joka ei ole MAUDEn (1966) mukaan niin tehokas kuin liotus.

Tässä tutkimuksessa pyrittiin selvittämään persiljan ja porkkanan siemenen mukana kulkeutuvat sienet ja erilaisten tiraami-käsittelyjen vaikutukset porkkanan siemenlevintäisiin sieniin ja taimettumiseen.

\section{Aineisto ja menetelmät}

Valtion siementarkastuslaitokselta ja eri siemenliikkeistä saatiin tutkimuksia varten persiljan ja porkkanan siemeniä, joista valittiin terveystarkastuksiin tärkeimmistä ja yleisimmistä lajikkeista 36 persiljan ja $\mathbf{5 7}$ porkkanan siemenerää (taulukko 1 ja 2). Siemenen alkuperää osoittavat lyhenteet ovat $\mathrm{Hg}=\mathrm{Ab}$ Hammenhögs Frö (Ruotsi), LD = L. Daehnfeldt (Tanska), OE = Ohlsen's Enke (Tanska), SG = Sluis en Groot (Hollanti) ja WW $=$ W. Weibull $\mathrm{Ab}$ (Ruotsi). Tarkastetut persiljan ja porkkanan siemenet ovat olleet Suomessa siemenkaupassa vuosina $1969-1975$.

Jokaisesta siemenerästä tutkittiin aluksi 200 siementä. Jos erässä oli tärkeitä sieniä, tutkittiin erästä 200 siementä lisää. Siementen idätys tapahtui $8 \times 25$ siemenen erissä Jacobsenin idätysaltaalla MÄKELÄn (1972) kuvaamalla menetelmällä. Itäminen ja siemenillä olevat sienet tutkittiin siemenkohtaisesti kaksi kertaa, 10 ja 14 vuorokautta kylvöstä. Tarvittaessa taimien kasvatusta jatkettiin petrimaljoissa ja sienistä tehtiin siirrostuksia PDA-alustalle sienen tarkempaa märittämistä tai patogeenisuuskokeita varten. Sienien määritys siemeniltä tehtiin stereo- ja valomikroskoopilla. Mikroskooppipreparaatit valmistettiin maitohappoon. Vaaleat sienet värjättiin valmisteella, jossa oli vettä $20 \mathrm{~g}$, fenolia $20 \mathrm{~g}$, maitohappoa $20 \mathrm{~g}$, glyserolia $40 \mathrm{~g}$ ja trypan-sinistä $0.05 \mathrm{~g}$. Persiljan siementen Septoria petroselini-pitoisuudet tutkittiin stereomikroskoopilla siemenkohtaisesti kaksi tuntia kostealla paperialustalla olleista 300 siemenestä.

Taimikasvatus- ja torjuntakokeissa porkkanan siemeniä kylvettiin $4 \times 100$ kpl steriloituun kvartsihiekkaan $14 \mathrm{~cm}: n$ muoviruukkuihin. Taimikasvatusaika oli korkeassa taimikasvatuslämpötilassa 3 viikkoa ja matalassa lämpötilassa 4.5 viikkoa. Taimikasvatukset korkeassa lämpötilassa tapahtuivat laboratoriossa, jossa vuorokautinen keskilämpötila oli n. $25^{\circ} \mathrm{C}$ ja suhteellinen kosteus $40-60 \%$, ja matalassa lämpötilassa Vötsch-merkkisessä kasvatuskaapissa, jossa vuorokautinen keskilämpötila oli $13^{\circ} \mathrm{C}$, yöllä 8 t $8^{\circ} \mathrm{C}$ ja päivällä $16 \mathrm{t}$ $15^{\circ} \mathrm{C}$ ja suhteellinen kosteus $90-95 \%$. Siemenkäsittelyt tehtiin $80 \%: 11 \mathrm{a}$ tiraami-valmisteella (Pomarsol Forte). Eri käsittelytavat ja -ajat ilmenevät 
Taulukko 1. Persiljan ja sen lajikkeiden yleisimmät siemenlevintäiset sienet. $\mathrm{A}=\%$ tutkituista siemeneristä saastunut, $\mathrm{B}=$ saastuneiden siemenerien keskimääräinen sienipitoisuus $\mathrm{kpl}$-\%:na, C = saastuneiden siemenerien sienipitoisuuksien (kpl-\%) vaihteluväli.

Table 1. Occurrence of the commonest seed-borne fungi on parsley and its varieties. $A=$ unit per cent of the seed lots infected, $B=$ mean of fungus capacity- $\%$ on the infected seed lots, $C=$ range of fungus capacity- $\%$ on the infected seed lots.
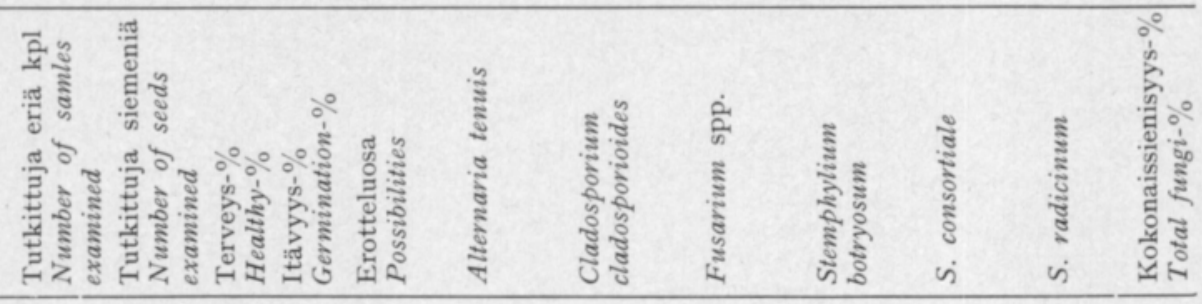

\begin{tabular}{|c|c|c|c|c|c|c|c|c|c|c|c|c|}
\hline $\begin{array}{l}\text { Persilja } \\
\text { Parsley }\end{array}$ & 36 & 4900 & 61 & 65.8 & $\begin{array}{l}\text { A } \\
\text { B } \\
\text { C }\end{array}$ & $\begin{array}{l}94 \\
19.3 \\
1-96\end{array}$ & $\begin{array}{l}47 \\
5.2 \\
1-27\end{array}$ & $\begin{array}{l}31 \\
4.7 \\
1-15\end{array}$ & $\begin{array}{l}19 \\
4.7 \\
1-16\end{array}$ & $\begin{array}{l}39 \\
2.4 \\
1-14\end{array}$ & $\begin{array}{l}39 \\
9.5 \\
1-63\end{array}$ & 55 \\
\hline Bravour OE & 7 & 900 & 57 & 72 & $\begin{array}{l}\text { A } \\
\text { B } \\
\text { C }\end{array}$ & $\begin{array}{l}86 \\
27.4 \\
1-93\end{array}$ & $\begin{array}{l}43 \\
3.3 \\
1-7\end{array}$ & $\begin{array}{l}57 \\
2.3 \\
1-4\end{array}$ & $\begin{array}{l}29 \\
3.0 \\
1-5\end{array}$ & $\begin{array}{l}29 \\
3.0 \\
3-3\end{array}$ & $\begin{array}{l}43 \\
6.0 \\
1-15\end{array}$ & 63 \\
\hline $\begin{array}{l}\text { Extra } \\
\text { mosskrusing } \mathrm{Hg}\end{array}$ & 4 & 500 & 81 & 60 & $\begin{array}{l}\text { A } \\
\text { B } \\
\text { C }\end{array}$ & $\begin{array}{l}100 \\
3.5 \\
1-6\end{array}$ & $\begin{array}{l}25 \\
2.0 \\
-\end{array}$ & $\begin{array}{l}0 \\
- \\
-\end{array}$ & ${ }_{-}^{0}$ & ${ }_{-}^{0}$ & $\begin{array}{l}50 \\
1.5 \\
1-2\end{array}$ & 23 \\
\hline Non plus ultra & 8 & 1300 & 42 & 71 & $\begin{array}{l}\text { A } \\
\text { B } \\
\text { C }\end{array}$ & $\begin{array}{l}100 \\
39.4 \\
7-96\end{array}$ & $\begin{array}{l}88 \\
2.4 \\
1-11\end{array}$ & $\begin{array}{l}50 \\
6.3 \\
1-15\end{array}$ & $\begin{array}{l}13 \\
5.0 \\
-\end{array}$ & ${ }^{0}-$ & $\begin{array}{l}50 \\
17.7 \\
2-63\end{array}$ & 78 \\
\hline Sammalpoimuinen & 10 & 1500 & 58 & 67 & $\begin{array}{l}\text { A } \\
\text { B } \\
\text { C }\end{array}$ & $\begin{array}{l}100 \\
21.6 \\
3-94\end{array}$ & $\begin{array}{l}40 \\
13.5 \\
1-27\end{array}$ & $\begin{array}{l}30 \\
2.3 \\
1-4\end{array}$ & $\begin{array}{l}30 \\
6.3 \\
1-16\end{array}$ & $\begin{array}{l}40 \\
4.3 \\
1-14\end{array}$ & $\begin{array}{l}20 \\
3.0 \\
1-15\end{array}$ & 67 \\
\hline $\begin{array}{l}\text { Muut lajikkeet } \\
\text { Other varieties }\end{array}$ & 7 & 700 & 79 & 66 & $\begin{array}{l}\text { A } \\
\text { B } \\
\text { C }\end{array}$ & $\begin{array}{l}86 \\
3.5 \\
1-6\end{array}$ & $\begin{array}{l}29 \\
1.5 \\
1-2\end{array}$ & $\begin{array}{l}0 \\
- \\
-\end{array}$ & $\begin{array}{l}14 \\
1.0 \\
-\end{array}$ & $\begin{array}{l}43 \\
1.0 \\
1-1\end{array}$ & $\begin{array}{l}43 \\
11.7 \\
2-30\end{array}$ & 22 \\
\hline
\end{tabular}

kuvasta 2. Tiraami-liotuksessa pidettiin $5 \mathrm{~g}$ siemeniä $200 \mathrm{ml}: \mathrm{ssa} 0.2 \%$ :ssa tiraami-suspensiossa $30^{\circ} \mathrm{C}$ :n lämpötilassa. Siemenen pintasterilointi tehtiin liottamalla $5 \mathrm{~g}$ siemeniä $200 \mathrm{ml}$ :ssa $1 \%$ :ssa natriumhypokloriitissa 10 minuuttia. Käsittelyjen jälkeen siemenet kuivattiin vuorokausi huoneen lämmössä suodatinpapereiden päällä. Kuivapeittauksessa torjunta-aine sekoitettiin ravistelemalla siemeniä lasipullossa. Kokeessa I oli lajikkeena Fancy Notabene 405, kokeessa II Nantes Notabene 20 ja kokeessa III Regulus Imperial.

Patogeenisuuskokeissa tutkittavia sieni-isolaatteja kasvatettiin 2 viikkoa huoneen lämmössä PDA-alustalla, josta sieni sekoitettiin $200 \mathrm{ml}$ :aan tislattua vettä Ultra-Turrax-homogenisaattorilla. Testikasvit, porkkanalla lajike Regulus Imperial ja persiljalla Sammallehtinen, kylvettiin muoviruukkuihin kvartsihiekkaan kutakin sieni-isolaattia kohden $4 \times 50$ siementä. Stemphylium 
Taulukko 2. Porkkanan ja sen lajikkeiden yleisimmät siemenlevintäiset sienet. $\mathrm{A}=\%$ tutkituista siemeneristä saastunut, $\mathrm{B}=$ saastuneiden siemenerien keskimääräinen sienipitoisuus $\mathrm{kpl}$ - $\%: \mathrm{na}, \mathrm{C}=$ saastuneiden siemenerien sienipitoisuuksien ( $\mathrm{kpl}-\%$ ) vaihteluväli.

Table 2. Occurrence of the commonest seed-borne fungi on carrot and its varieties. $A=u n i t$ per cent of the seed lots infected, $B=$ mean of fungus capacity- $\%$ on the infected seed lots, $C=$ range of fungus capacity- $\%$ on the infected seed lots.
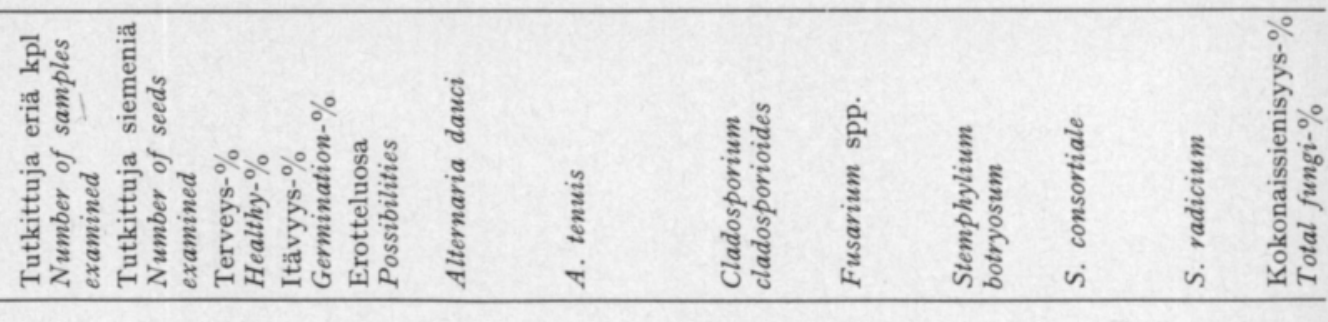

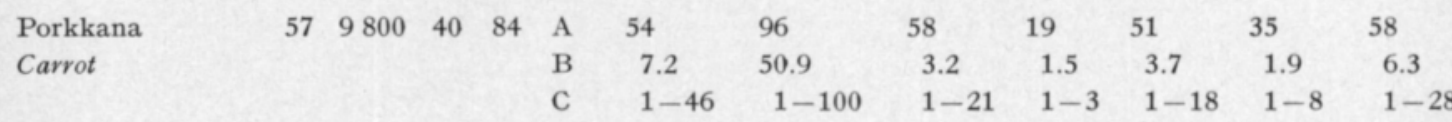

\begin{tabular}{|c|c|c|c|c|c|c|c|c|c|c|c|c|}
\hline $\begin{array}{l}\text { Amager Ny } \\
\text { Munkegård } \mathrm{OE}\end{array}$ & 6 & 1500 & 21 & 79 & $\begin{array}{l}\mathrm{A} \\
\mathrm{B} \\
\mathrm{C}\end{array}$ & $\begin{array}{l}100 \\
\begin{array}{l}2.2 \\
1-5\end{array}\end{array}$ & $\begin{array}{l}100 \\
69.0 \\
56-93\end{array}$ & $\begin{array}{l}17 \\
1.0 \\
-\end{array}$ & $\begin{array}{r}17 \\
1.0 \\
-\end{array}$ & $\begin{array}{l}33 \\
2.0 \\
1-3\end{array}$ & $\begin{array}{l}33 \\
3.0 \\
2-4\end{array}$ & $\begin{array}{l}83 \\
8.4 \\
1-28\end{array}$ \\
\hline $\begin{array}{l}\text { Amsterdamer } \\
\text { No } 378 \mathrm{OE}\end{array}$ & 8 & 1300 & 55 & 84 & $\begin{array}{l}\text { A } \\
\text { B } \\
\text { C }\end{array}$ & $\begin{array}{l}25 \\
1.0 \\
1-1\end{array}$ & $\begin{array}{l}100 \\
32.3 \\
2-89\end{array}$ & $\begin{array}{l}25 \\
1.0 \\
1-1\end{array}$ & $\begin{array}{l}13 \\
1.0 \\
-\end{array}$ & $\begin{array}{l}38 \\
1.7 \\
1-2\end{array}$ & $\begin{array}{l}0 \\
- \\
-\end{array}$ & $\begin{array}{l}25 \\
20.5 \\
17-24\end{array}$ \\
\hline Fancy OE & 10 & 1700 & 31 & 80 & $\begin{array}{l}\mathrm{A} \\
\mathrm{B} \\
\mathrm{C}\end{array}$ & $\begin{array}{l}60 \\
11.3 \\
2-46\end{array}$ & $\begin{array}{l}90 \\
64.7 \\
4-97\end{array}$ & $\begin{array}{l}60 \\
4.3 \\
1-13\end{array}$ & $\begin{array}{l}40 \\
1.0 \\
1-1\end{array}$ & $\begin{array}{l}10 \\
1.0 \\
-\end{array}$ & $\begin{array}{l}30 \\
1.6 \\
1-2\end{array}$ & $\begin{array}{l}60 \\
4.0 \\
1-8\end{array}$ \\
\hline Feonia LD & 6 & 1100 & 30 & 84 & $\begin{array}{l}\mathrm{A} \\
\mathrm{B} \\
\mathrm{C}\end{array}$ & $\begin{array}{l}50 \\
11.0 \\
6-13\end{array}$ & $\begin{array}{l}100 \\
54.2 \\
11-97\end{array}$ & $\begin{array}{l}67 \\
1.0 \\
1-1\end{array}$ & $\begin{array}{l}50 \\
2.0 \\
1-3\end{array}$ & $\begin{array}{l}67 \\
3.8 \\
1-7\end{array}$ & $\begin{array}{l}33 \\
1.0 \\
1-1\end{array}$ & $\begin{array}{l}83 \\
8.0 \\
2-18\end{array}$ \\
\hline $\begin{array}{l}\text { Nantes Notabene } \\
\text { No } 20 \text { OE }\end{array}$ & 8 & 1400 & 34 & 85 & $\begin{array}{l}\text { A } \\
\text { B } \\
\text { C }\end{array}$ & $\begin{array}{l}63 \\
9.6 \\
1-31\end{array}$ & $\begin{array}{l}100 \\
54.0 \\
6-100\end{array}$ & $\begin{array}{l}100 \\
2.3 \\
1-9\end{array}$ & $\begin{array}{l}13 \\
2.0 \\
-\end{array}$ & $\begin{array}{l}38 \\
4.3 \\
1-10\end{array}$ & $\begin{array}{l}63 \\
2.6 \\
1-8\end{array}$ & $\begin{array}{l}63 \\
2.2 \\
1-4\end{array}$ \\
\hline $\begin{array}{l}\text { Nantes Typ Top } \\
\text { Sg }\end{array}$ & 4 & 500 & 56 & 87 & $\begin{array}{l}\mathrm{A} \\
\mathrm{B} \\
\mathrm{C}\end{array}$ & $\begin{array}{r}25 \\
4.0 \\
-\end{array}$ & $\begin{array}{l}100 \\
37.8 \\
6-98\end{array}$ & $\begin{array}{l}75 \\
9.0 \\
1-21\end{array}$ & $\begin{array}{l}0 \\
- \\
-\end{array}$ & $\begin{array}{l}50 \\
10.0 \\
2-18\end{array}$ & $\begin{array}{l}0 \\
- \\
-\end{array}$ & $\begin{array}{l}50 \\
8.5 \\
13-14\end{array}$ \\
\hline $\begin{array}{l}\text { Regulus Imperial } \\
\text { WW }\end{array}$ & 6 & 1400 & 62 & 86 & $\begin{array}{l}\mathrm{A} \\
\mathrm{B} \\
\mathrm{C}\end{array}$ & $\begin{array}{l}67 \\
7.3 \\
2-19\end{array}$ & $\begin{array}{l}100 \\
28.3 \\
1-59\end{array}$ & $\begin{array}{l}67 \\
1.5 \\
1-3\end{array}$ & $\begin{array}{r}17 \\
1.0 \\
-\end{array}$ & $\begin{array}{r}17 \\
1.0 \\
-\end{array}$ & $\begin{array}{l}50 \\
1.3 \\
1-2\end{array}$ & $\begin{array}{l}50 \\
2.0 \\
1-3\end{array}$ \\
\hline $\begin{array}{l}\text { Muut lajikkeet } \\
\text { Other varieties }\end{array}$ & 9 & 900 & 39 & 84 & $\begin{array}{l}\text { A } \\
\text { B } \\
\text { C }\end{array}$ & $\begin{array}{l}33 \\
2.0 \\
1-2\end{array}$ & $\begin{array}{l}89 \\
55.0 \\
15-100\end{array}$ & $\begin{array}{l}33 \\
6.0 \\
3-9\end{array}$ & $\begin{array}{r}11 \\
1.0 \\
-\end{array}$ & $\begin{array}{l}66 \\
3.7 \\
1-5\end{array}$ & $\begin{array}{r}11 \\
1.0 \\
-\end{array}$ & $\begin{array}{l}33 \\
8.0 \\
6-11\end{array}$ \\
\hline
\end{tabular}


Taulukko 3. Alternaria dauci-, A. tenuis- ja Stemphylium radicinum-sienien vaikutus persiljan ja porkkanan itämiseen ja taimien kuolemiseen Jacobsenin idätysaltaalla.

$\mathrm{A}=$ itäneet siemenet, $\mathrm{B}=$ itämättömät siemenet, $\mathrm{C}=$ elävät taimet, $\mathrm{D}=$ kuolleet taimet. Table 3. Effect of Alternaria dauci, A. tenuis and Stemphylium radicinum on germination and occurrence of dead seedlings in Jacobsen's germinator.

$A=$ germinated seeds, $B=$ ungerminated seeds, $C=$ living seedlings, $D=$ ded seedlings.

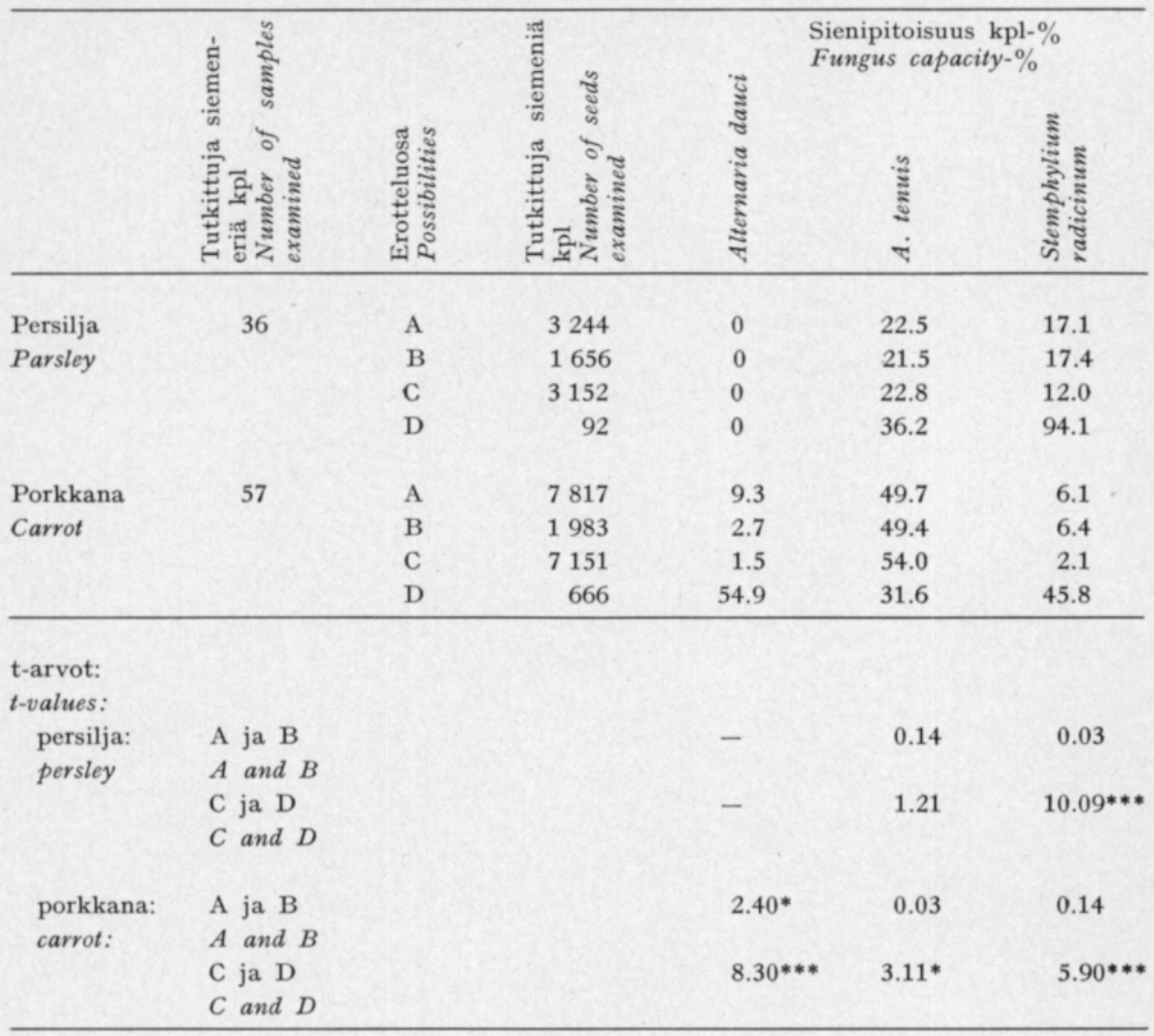

radicinum 'persilja' oli eristetty persiljalta Bravour-lajikkeelta, S. radicinum 'porkkana' ja Alternaria dauci porkkanalta Nantes Notabene 20-lajikkeelta. Sienisuspensiota pipetoitiin 2 viikon ikäisille taimille 1 tippa/taimi. Taimet eristettiin inokuloinnin jälkeen muovikalvolla 2 viikoksi.

Siemenen terveysprosentti (taulukot 1 ja 2) tarkoittaa täysin terveiden siementen määrää tutkituista siemenistä. Itävyysprosentti määritettiin 14 vuorokautta kylvöstä. Kokonaissienisyysprosentti on erän kaikkien sienien määrä tutkituista siemenistä. Alternaria dauci-, A. tenuis- ja Stemphylium radiciunm-sienien esiintymisrunsaus itäneillä ja itämättömillä, elävillä ja kuolleilla taimilla 14 vuorokautta kylvöstä on testattu t-testillä. Taimikasvatus- ja torjuntakokeiden tulokset on testattu varianssianalyysilla.

Tutkimukset tehtiin vuosina $1971-72$ ja $1974-75$. Vuonna 1971 sienimääritykset teki dosentti MMT Kaiho Mäkelä Septoria-määrityksiä lukuunottamatta ja muina vuosina tekijä. 
Taulukko 4. Persiljan siemenen Septoria petroselini-pitoisuudet.

Table 4. Occurence of Septoria petroselini on seed lots of parsley.

\begin{tabular}{|c|c|c|c|c|}
\hline \multirow{2}{*}{$\begin{array}{l}\text { Lajike } \\
\text { Variety }\end{array}$} & \multirow{2}{*}{$\begin{array}{c}\text { Tutkittuja } \\
\text { eriä kpl } \\
\text { Number of } \\
\text { seed lots }\end{array}$} & \multirow{2}{*}{$\begin{array}{l}\text { Sairaita } \\
\text { eriä kpl } \\
\text { Number of } \\
\text { disease lots }\end{array}$} & \multicolumn{2}{|c|}{ Septoria petroselini - $\%$} \\
\hline & & & $\begin{array}{c}\text { Keskiarvo } \\
\text { Mean }\end{array}$ & $\begin{array}{c}\text { Vaihteluväli } \\
\text { Range }\end{array}$ \\
\hline 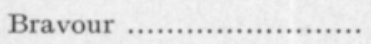 & 9 & 9 & 15.7 & $8.3-21.4$ \\
\hline Non plus ultra ................. & 7 & 7 & 8.1 & $3.0-16.3$ \\
\hline Sammalpoimune...$\ldots \ldots \ldots \ldots$ & 11 & 10 & 16.4 & $3.0-36.8$ \\
\hline
\end{tabular}

Taulukko 5. Persiljan ja porkkanan muut siemenlevintäiset sienet. $\mathrm{A}=\%$ tutkituista siemeneristä saastunut, $\mathrm{B}=$ saastuneiden siemenerien keskimääräinen sienipitoisuus $\mathrm{kpl}$ - $\%$ :na, $\mathrm{C}=$ saastuneiden siemenerien sienipitoisuuksien ( $\mathrm{kpl}-\%$ ) vaihteluväli.

Table 5. Occurrence of the other seed-borne fungi on parsley and carrot. $A=$ unit per cent of the seed lots infected, $B=$ mean of fungus capacity- $\%$ on the infected seed lots, $C=$ range of fungus capacity- $\%$ on the infected seed lots.

\begin{tabular}{|c|c|c|c|c|c|c|}
\hline \multirow[t]{2}{*}{$\begin{array}{l}\text { Sieni } \\
\text { Fungus }\end{array}$} & \multirow[b]{2}{*}{ A } & \multicolumn{2}{|c|}{$\begin{array}{l}\text { Persilja } \\
\text { Parsley }\end{array}$} & \multicolumn{3}{|c|}{$\begin{array}{c}\text { Porkkana } \\
\text { Carrot }\end{array}$} \\
\hline & & B & C & A & B & C \\
\hline Acremoniella atra $\ldots \ldots \ldots \ldots \ldots$ & 3 & 1.0 & - & 30 & 6.1 & $1-39$ \\
\hline $\begin{array}{l}\text { Actinomucor spp. }+\ldots \ldots \ldots \ldots \\
\text { Mucor spp. }\end{array}$ & 19 & 8.3 & $1-64$ & 11 & 1.0 & $1-1$ \\
\hline Aspergillus spp. ................... & 25 & 8.3 & $1-64$ & 11 & 1.0 & $1-1$ \\
\hline Cephalosporium spp. ............. & 8 & 2.7 & $2-4$ & 21 & 1.9 & $1-4$ \\
\hline Chaetomium indicum ............. & 6 & 2.0 & $1-3$ & 2 & 1.0 & - \\
\hline Dendryphion nanum ............. & 3 & 1.0 & - & - & - & - \\
\hline Epicoccum purpurascens ........ & 33 & 2.2 & $1-27$ & 54 & 2.5 & $1-11$ \\
\hline Gonatobotrys simplex ............. & 14 & 16.6 & $5-39$ & 26 & 2.9 & $1-14$ \\
\hline 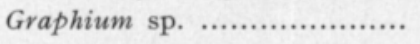 & 3 & 1.0 & - & - & - & - \\
\hline Helminthosporium sativum ..... & 3 & 1.0 & - & 2 & 3.0 & - \\
\hline 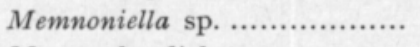 & 3 & 1.0 & - & - & - & - \\
\hline Mycotypha dichotoma ............ & 3 & 3 & - & - & - & - \\
\hline Oedocephalum sp. ................... & - & - & - & 9 & 1.0 & $1-2$ \\
\hline Papularia sphaerosperma ...... & 3 & 1.0 & - & 2 & 1.0 & - \\
\hline Penicilliim spp. ................... & 58 & 5.9 & $1-26$ & 53 & 3.5 & $1-18$ \\
\hline Phoma spp. ............................ & 8 & 1.3 & $1-2$ & 5 & 1.0 & $1-1$ \\
\hline Rhizopus nigricans ................. & 22 & 4.9 & $1-21$ & 56 & 1.2 & $1-2$ \\
\hline 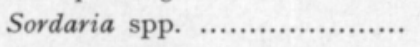 & 11 & 1 & $1-1$ & 2 & 1.0 & - \\
\hline 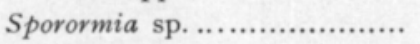 & 3 & 1 & - & - & - & - \\
\hline Stachybotrys atra ..................... & 17 & 2.5 & $1-4$ & 54 & 2.8 & $1-29$ \\
\hline Torula herbarum ................... & 3 & 1.0 & - & - & - & - \\
\hline Trichoderma viride .................. & 17 & 1.8 & $1-4$ & 2 & 1.0 & - \\
\hline Trichothecium roseum ............ & 11 & 1.6 & $1-2$ & 5 & 3.7 & $1-9$ \\
\hline
\end{tabular}

\section{Tulokset}

Persiljan ja porkkanan siemeniltä tavattiin 30 sienisukua, joista 3 kuului Phycomycetes- ja 3 Ascomycetes-sieniluokkaan. Loput 24 sienisukua kuuluivat Fungi imperfecti-muotoluokkaan. Edellisten lisäksi tavattiin siemeniltä tarkemmin määrittämättömiä Streptomycetes-sädesieniä ja Myxomycetes-limasieniä. 
Porkkanan siemenillä oli runsaammin sieniä kuin persiljalla (taulukot 1 ja 2 ). Persiljalajikkeista oli tervein Extra mosskrussig II ja sairain No plus vltra. Porkkanalla oli tervein lajike Regulus Imperial ja sairain Amager Ny Munkegård.

\section{Siemenlevintäiset sienet persiljalla ja porkkanalla}

Persiljan ja porkkanan siemeniltä tavattiin seuraavat sienisuvut ja -lajit (taulukko 1, 2, 4 ja 5):

Phycomycetes

Actinomucor spp. ja Mucor spp.

Rhizopus nigricans Ehrenb.

Mycotypha dichotoma Wolf

Ascomycetes

Chaetomium indicum Corda

Sordaria spp.

Sporormia sp.

Fungi imperfecti

Acremoniella atra (Corda) Sacc.

Alternaria dauci (Kühn) Groves \& Skolko (kuva 3 a) oli $54 \%$ :ssa porkkanaeristä keskimäärin 7.2\%:n pitoisuutena. Lajikkeen Amager Ny Munkegård kaikki erät olivat tämän sienen infektoimia. Yhdessä Fancy-lajikkeen erässä oli $46 \%$ sientä. A. dauci oli useimmin itäneillä kuin itämättömillä siemenillä. Neljätoista vuorokautta kylvöstä se oli useimmin kuolleilla kuin elävillä taimilla (taulukko 3). Patogeenisuuskokeessa sieni oli voimakas taimipoltteen aiheuttaja porkkanalla (kuva 1).

Alternaria tenuis auct. oli sekä persiljalla että porkkanalla yleisin siemenlevintäinen sieni. Se oli yli $90 \%$ :ssa tutkituista eristä. Keskimääräinen sienipitoisuus oli persiljalla $19.5 \%$ ja porkkanalla $50.9 \%$. Sieni oli itäneillä ja itämättömillä yhtä runsaana. Porkkanalla oli $A$. tenuis useimmin elävillä kuin kuolleilla taimilla (taulukko 3 ). Sieni ei iskeytynyt idätyksissä taimiin, vaan rajoittui siemenkuoren pinnalle.

Aspergillus spp.

Cephalosporium spp.

Cladosporium cladosporioides (Fres) de Verie

Epicoccum purpurascens Ehrenb. ex Sehlecht.

Fusarium spp. -sieniä oli persiljalla $31 \%$ :ssa keskimäärin alle $5 \%$ :n ja porkkanalla $19 \%$ :ssa siemeneristä alle $2 \%$ :n pitoisuuksina. Yleisin laji oli F. avenaceum (Fr.) Sacc., joka ei patogeenisuuskokeessa aiheuttanut porkkanalle taimipoltetta, mutta teki juuriin pieniä ruskeita laikkuja.

Gonatobotrys simplex Corda

Graphium sp.

Helminthosporium sativum Pammel, King \& Bakke

Memnoniella sp. 


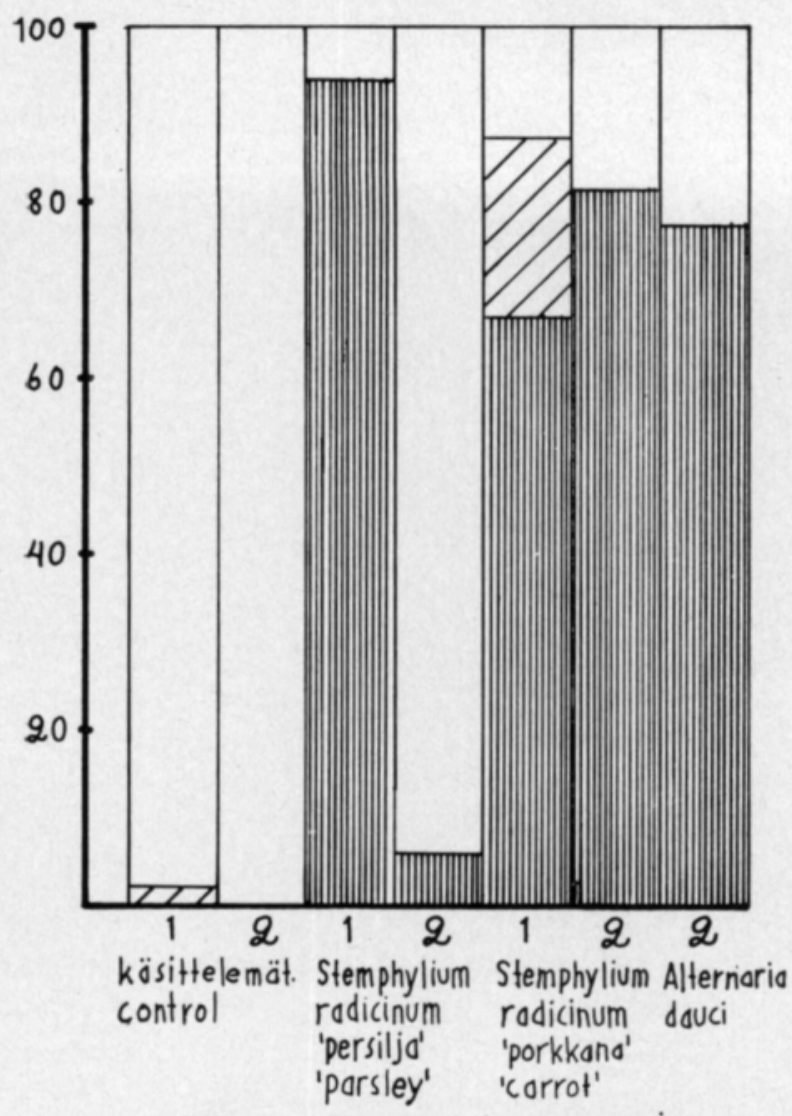

$\square$ terveita Eaviottuneita $\mathbf{m}$ mkuolleita taimie healthy damaqed dead seedlings
Kuva 1. Alternaria dauci- ja Stemphylium radicinum-sienen patogeenisuus persiljalla (1) ja porkkanalla (2). Fig. 1. Pathogenicity of Alternaria dauci and Stemphylium radicinum to parsley (1) and carrot (2).

Oedocephalum sp.

Papularia sphaerosperma (Pers.) Höhnel

Penicillium spp.

Phoma spp.

Scopulariopsis sp.

Septoria petroselini Desm. (kuva $3 \mathrm{c}$ ja d) oli hyvin yleinen sieni persiljan siemenillä. Tutkituista 26 erästä 25:ssä oli tämä sieni $3-37 \%$ :n pitoisuuksina (taulukko 4).

\section{Stachybotrys atra Corda}

Stemphylium botryosum Wall., jonka koteloaste on Pleospora herbarum (Pers.) Rabenh., oli $19 \%$ :ssa persiljan ja $51 \%$ :ssa porkkanan siemeneristä 1-14\%:n pitoisuuksissa.

Stemphylium radicinum (Meier, Drechsler \& Eddy) Neergaard (kuva 3 b) oli $39 \%$ :ssa persiljan ja $58 \%$ :ssa porkkanan eristä. Erien keskimääräinen sienipitoisuus oli persiljalla $10 \%$ ja porkkanalla $6 \%$. Yhdellä persiljaerällä oli tätä sientä $63 \%$. Sieni oli yhtä runsaana itäneillä ja itämättömillä siemenillä. 


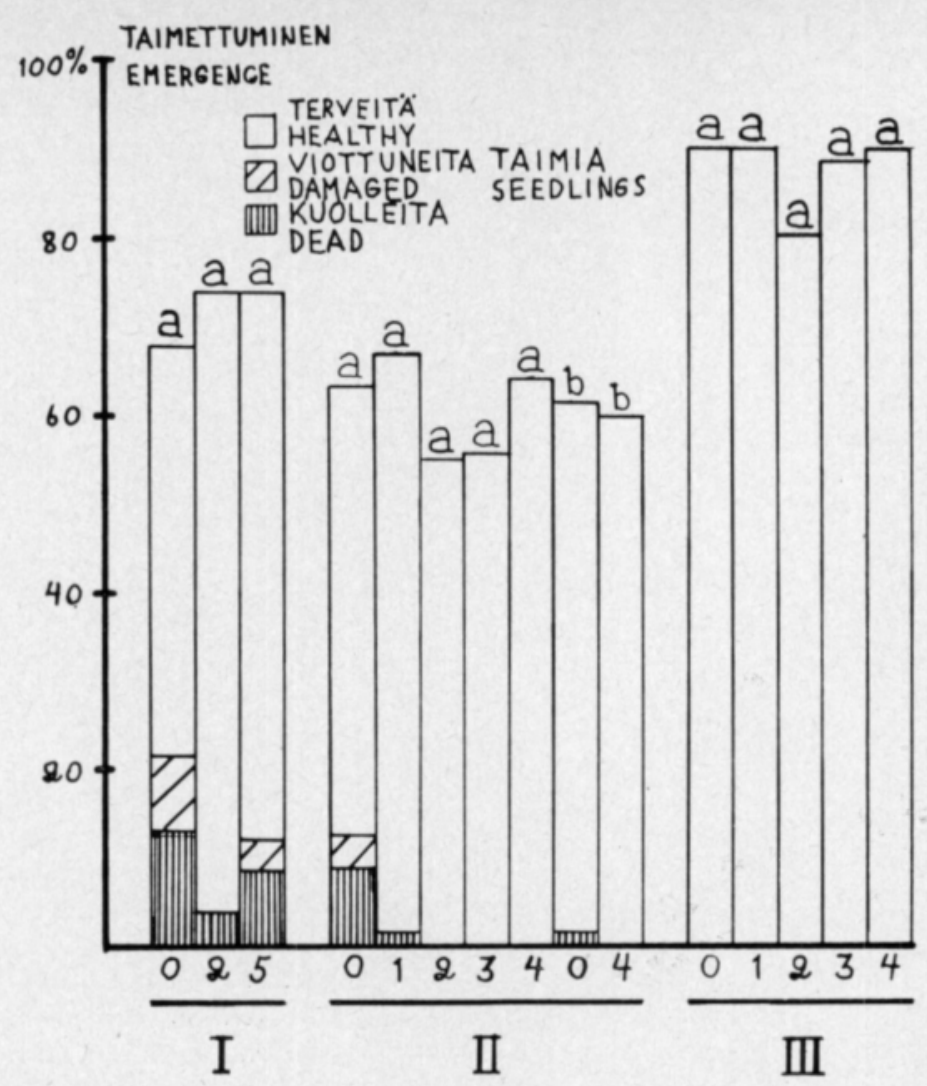

Kuva 2. Siemenkäsittelyjen ja lämpötilan vaikutus taimipoltteeseen ja taimettumiseen porkkanalla. $0=$ käsittelemätön, $1=$ tiraami-kuivapeittaus $5 \mathrm{~g}$ Pomarsol Forte/ $1 \mathrm{~kg}$ siemeniä, $2=0.2 \%$ tiraami-liotus $24 \mathrm{t} 30^{\circ} \mathrm{C}: \mathrm{ssa}, 3=$ tiraami-liotus $12 \mathrm{t}, 4=$ tiraami-liotus $6 \mathrm{t}, 5=$ $1 \%$ NaClO-liotus 10 min., a = kasvatuslämpötila $25^{\circ} \mathrm{C}, \mathrm{b}=$ kasvatuslämpötilä $13^{\circ} \mathrm{C}$, koe I: siemenessä $46 \%$ Alternaria dauci ja $6 \%$ Stemphylium radicinum, koe II: siemenessä $31 \%$ Alternaria dauci ja $2 \%$ Stemphylium radicinum, koe III: terve siemen.

F-arvot taimettuminen: $\mathrm{I}=0.97, \mathrm{II}: 7.20^{* * *}, \mathrm{III}=4.23 * *$

terveet taimet: $\mathrm{I}=15.07^{* *}, \mathrm{II}=9.57^{*}$, a ja $\mathrm{b}=10.59 * *$

Fig. 2. Effect of seed treatments and temperature on the damping-off and emergence of seedlings of carrot. $0=$ control, $1=$ thiram dust $5 \mathrm{~g}$ Pomarsol Forte $1 \mathrm{~kg}$ seeds, $2=0.2 \%$ thiram soak for $24 \mathrm{~h}$ at $30^{\circ} \mathrm{C}, 3=$ thiram soak for $12 \mathrm{~h}, 4=$ thiram soak for $6 \mathrm{~h}, 5=1.0 \% \mathrm{NaClO}$ soak for 10 min., $a=$ growtemperature $25^{\circ} \mathrm{C}, b=$ growthtemperature $13^{\circ} \mathrm{C}$, test $\mathrm{I}: 46 \%$ Alternaria dauci and $6 \%$ Stemphylium radicinum on seeds, test $I I: 31 \% A$. dauci and $2 \%$ S. radicinum on seeds, test III: healthy seeds.

F-values: emergence of seedlings: $I=0,97, I I=7.20^{* * *}, I I I=4.23 * *$

healthy seedlings $\quad I=15.07^{* *}, I I=15.57^{*}, a$ and $b 10,59 * *$

Kaksi viikkoa kylvöstä oli S. radicinum useimmin kuolleilla kuin elävillä taimilla (taulukko 3). Persiljalta eristetty $S$. radicnium oli erittäin voimakas patogeeni persiljan taimille, mutta vioitti vain lievästi porkkanan taimia. Porkkanalta eristetty $S$. radicinum oli patogeeninen sekä persiljalle että porkkanalle (kuva 1).

Torula herbarum (Pers.) Link

Trichoderma viride Pers. ex Fr.

Trichothecium roseum Link ex Fries 


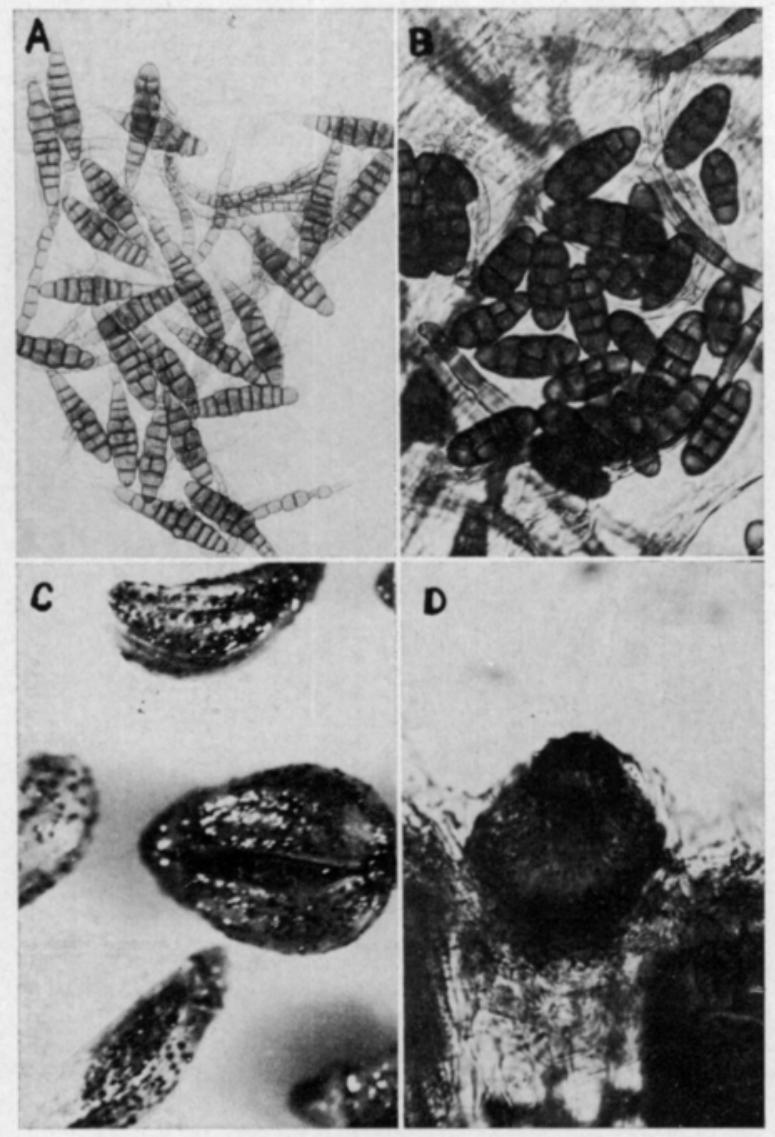

Kuva 3. a: Alternaria dauci, $200 \mathrm{x}$, b: Stemphylium radicinum, $450 \mathrm{x}$, c: Septoria petroselini kuromapulloja siemenen pinalla, d: S. petroselini, kuromapullo $450 \mathrm{x}$.

Fig. 3. a: Alternaria dauci, $200 x, b$ : Stemphylium radicinum, $450 x, c$ : Septoria petroselini, pycnidiums on surface of seeds, $d$ : S. petroselini, pycnidium $450 x$.

\section{Taimikasvatus ja torjuntakokeet}

Taimikasvatuksessa sekä Alternaria dauci että Stemphylium radicinum aiheuttivat porkkanalla taimipoltetta $25^{\circ} \mathrm{C}$ :n lämpötilassa, mutta alhaisessa lämpötilassa, $13^{\circ} \mathrm{C}: s s a$, sienen aiheuttamat tuhot jäivät vähäisiksi (kuva 2, koe II). Kaikki siemenen tiraami-käsittelytavat vähensivät erittäin merkitsevästi taimipoltteisten ja vioittuneiden taimien määrää. Siemenen tiraamiliotus 12 ja 24 tuntia alensi taimettumista merkittävästi sekä sairailla että terveillä siemenillä (kuva 2, koe II ja III).

\section{Tulosten tarkastelu}

Porkkanan siementen Alternaria dauci- ja Stemphylium radicinum-pitoisuudet olivat samaa suuruusluokkaa kuin HALKILAHDEN (1972) selvityksessä. Persiljan Septoria petroselini- ja S. radicinum-pitoisuudet olivat keskimäärin samoja kuin NeERgaArdin $(1950,1951)$ tutkimuksissa. NEERgAard (1945) on erottanut persiljalla olevan S. radicium-sienen omaksi muunnokseksi, S. radinum var. petroselini Neergaard, jonka kuromakoko on suurempi kuin S. radicicinum-sienellä. Keskimääräinen kuromakoko oli nyt porkkanalta eristetyllä S. radicium -sienellä $32 \times 15 \mu$ ja persiljalta eristetyllä $39 \times 17 \mu$. Koska 
patogeenisuuskokeenkin tulokset olivat samansuuntaiset kuin NEERgAARDilla (1945, p. 352), on persiljalta eristetty S. radicinum todennäköisesti edellämainittu muunnos.

Muista kirjallisuudessa mainituista (NoBle ja RichARDSON 1968) persiljan ja porkkanan siemenlevintäisistä taudeista tavattiin tässä tutkimuksessa Alternaria tenuis, Fusarium avenaceum, Phoma sp., Stemphylium botryosum ja $S$. consortiale. Useimmat muista persiljan ja porkkanan siemeniltä nyt löydetyistä sienistä ovat myös muiden kasvien siemenillä yleisiä (MALonE ja MusketT 1964, YLIMÄKI 1970, MÄKELÄ 1972).

Suomessa suositeltu vihanneskasvien siementen tiraami-kuivapeittaus on nyt suoritettujen kokeiden mukaan tehokas porkkanan siemenlevintäisiä sieniä vastaan. Mahdollisesti tehokkaampi tiraami-liotus ei ole aiheellinen, koska se ilmeisesti alentaa saatujen tulosten mukaan taimettumista ja on käytännön viljelmillä vaikeampi toteuttaa kuin normaali kuivapeittaus. Lisäksi Suomessa on porkkanan kylvöaikana toukokuussa riittävän viileätä vähentämään A. dauci- ja S. radicinum-sienen aiheuttamaa taimipoltetta. Näiden sienien kasvun lämpötilaoptimi on n. $28^{\circ} \mathrm{C}$ (NEERGAARD 1945). Nyt tehtyjen kokeiden mukaan $13^{\circ} \mathrm{C}$ :n keskilämpötila taimettumisessa vähentää melko tehokkaasti taimipoltetta.

Persiljan siemenen tiraami-kuivapeittaus tehoaa todennäköisesti myös $S$. radicinum var. petroselini -sieneen, mutta Septoria petroselini-sienen torjumiseksi pitäisi tehdä tarkempia tutkimuksia sienen taloudellisen merkityksen takia. Samoin porkkanan siemenen mukana kulkeutuvien sienien merkitys varastotautien määrään olisi selvitettävä, sillä S. radicinum- ja Fusariumsienet ovat merkittäviä porkkanan varastotautien aiheuttajia (MUKULA 1957).

\section{Tiivistelmä}

Suomeen tuotavien persiljan ja porkkanan siemenien mukana kulkeutuvien sienien selvittämiseksi tutkittiin vuosina 1969-75 kaupassa olleista persiljan siemenistä 36 erää ja porkkanan siemenistä 57 erää. Siemeniä idätettiin Jacobsenin idätysaltaalla, josta sienet tutkittiin siemenkohtaisesti stereo- ja valomikroskoopilla. Siemenen eriaikaisten tiraami-liotusten $30^{\circ} \mathrm{C}: s s a$ ja tiraami-kuivapeittauksen sekä taimettumislämpötilan vaikutus porkkanan siemenlevintäisiin sieniin on testattu.

Alternaria dauci (Kühn) Groves \& Skolko oli $54 \%$ :ssa porkkanaeristä keskimäärin $7.2 \%$ :n pitoisuuksina. Sieni oli voimakas taimipoltteen aiheuttaja porkkanalla.

Stemphylium radicinum (Meier, Drechsler \& Eddy) Neergaard oli $39 \%$ :ssa persiljan ja $58 \%$ :ssa porkkanan siemeneristä. Keskimääräinen sienipitoisuus oli persiljalla $10 \%$ ja porkkanalla $6 \%$. Sieni oli voimakas taimipoltteen aiheuttaja. Persiljalta eristetty $S$. radicinum oli sienen muunnos S. radicinum var. petroselini Neergaard, joka oli persiljalle voimakas patogeeni, mutta vioitti porkkanaa heikosti.

Septoria petroselini Desm. oli kaikissa persiljaerissä yhtä lukuunottamatta $3-37 \%$ :n pitoisuuksina. 
Persiljan ja porkkanan siemeniltä löydettiin edellisten lisäksi 31 muuta sienisukua ja -lajia, joista yleisin oli Alternaria tenuis auct. Näillä sienillä ei ollut merkitystä itämisessä ja taimettumisessa.

Porkkanan siemenen liotus $0.2 \%$ :ssa tiraami-suspensiossa 6,12 ja 24 tuntia $30^{\circ}$ C:ssa sekä tiraami-kuivapeittaus estivät Alternaria dauci- ja Stemphylium radicinum-sienien aiheuttaman taimipoltteen, mutta kaksi pisintä liotusaikaa alensivat taimettumista sekä sairailla että terveillä siemenillä. Alhainen taimettumislämpötila, $13^{\circ} \mathrm{C}$, vähensi $A$. dauci- ja $S$. radicinum-sienen aiheuttamaa taimipoltetta.

\section{KIRJALLISUUSLUETTELO}

Halкilıнti, A. M. 1972. Porkkanan siementavaran terveydestä. Valtion siementarkastuslaitos 1969/1970, Maatilahall. Tied. 371: 29-31.

Malone, J. P. \& Muskett, A. E. 1964. Seed-borne fungi. Proc. Int. Seed Test. Ass. 29: 179384.

MAUDE, R. B. 1966. Studies on the etiology of carrot rot, Stemphylium radisinum (Meier, Drechsl. \& Eddy) Neerg., and leaf blight, Alternaria dauci (Kühn) Groves \& Skolko, on carrot crops; and on fungicide control of their seed-borne infection phases. Ann. Appl. Biol. 57: 83-93.

Mukula, J. 1957. On the decay of stored carrots in Finland. Acta Agric. Scand., Suppl. 2: $1-132$.

MÃKELÃ, K. 1972. Seed borne fungi on cultivated grasses in Finland. Acta Agr. Fenn. 124, $1-44$.

NeergaArd, P. 1945. Danish species of Alternaria and Stemphylium. 560 p. Copenhagen.

- - 1950. 14. Ársberetning fra J. E. Ohlsens Enkes Plantepatologiske laboratorium 1. august $1948-31$. juli 1949.23 p. København.

_- - 1951. 15. og sidsta Årsberetning fra J. E. Ohlsens Enkes Plantepatologiske laboratorium 1. august $1949-31$, juli 1950.33 p. København.

YLıмйKI, A. 1970. The microflora of cereal seeds in Finland. Ann. Agric. Fenn. 9: 293-295.

YLLÖ, L. 1972. Valtion siementarkastuslaitos 1970/1971. Maatilahall. Tied. 373:1-28.

- - 1973. Valtion siemetarkastuslaitos 1971/1972. Maatilahall. Tied. 377: 1-25.

_- 1975. Valtion siementarkastuslaitos 1973/1974. Maatilahall. Tied. 381: 1-32.

- - 1976. Valtion siementarkastuslaitos 1974/1975. Maatilahall. Tied. 382: 1-35.

Käsikirjoitus saapunut 3.2.1978 